Disponível em:

http://editora.unoesc.edu.br/index.php/race

Race, Joaçaba, v. 15, n. 2, p. 531-552, maio/ago. 2016

\title{
EMPREENDEDORISMO INTERNACIONAL: UMA ANÁLISE DE EXPORTADORAS DO SEMIÁRIDO NORDESTINO
}

International entrepreneurship: an analysis of exporting the Northeastern Semiarid

\section{Yákara Vasconcelos Pereira Leite \\ E-mail: yakarav@gmail.com}

Doutora e Mestre em Administração pela Universidade Federal de Pernambuco; Professora Adjunta do curso de Administração; Coordenadora da Especialização em Gestão Estratégica de Serviços da Universidade Federal Rural do Semi-Árido.

\section{Walter Fernando Araújo de Moraes}

E-mail: walter.moraes@ufpe.br Doutor em Management Sciences pela University of Manchester Institute of Science and Techonology; Mestre em Engenharia de Produção pela Universidade Federal de Santa Catarina; Diretor Acadêmico da Faculdade Boa Viagem; Coordenador do Programa de Pós-Graduação em Administração, Cursos de Mestrado e Doutorado.

Viviane Santos Salazar

E-mail: viviane_salazar@yahoo.com.br Mestre e Doutora em Administração pela Universidade Federal de Pernambuco; Professora Adjunto I do Departamento de Hotelaria e Turismo da Universidade Federal de Pernambuco. Endereço para contato: Avenida Professor Moraes Rego, 1235, Cidade Universitária, 50670-901, Recife, Pernambuco, Brasil.

Artigo recebido em 09 de fevereiro de 2015. Aceito em 01 de fevereiro de 2016. 
Resumo

Nesta pesquisa teve-se o objetivo geral de analisar o empreendedorismo internacional nas exportadoras de frutas localizadas no Semiárido Nordestino. O estudo de múltiplos casos de modo longitudinal foi desenvolvido com base na perspectiva qualitativa. Empresas de quatro Estados do Semiárido Nordestino foram analisadas, a saber: Agrícola Famosa, Agro Melão (pseudônimo), Special Fruit e Ara Agrícola. Trinta gestores e consultores participaram das entrevistas semiestruturadas, examinadas com apoio da análise de conteúdo. Os resultados indicam que a comercialização arrojada é uma dimensão do empreendedorismo internacional que emergiu na fase empírica da investigação. A ausência de contratos e a centralização das atividades por parte do empreendedor são as propriedades da comercialização arrojada. Esses achados são relevantes para a área de conhecimento da Administração por revelarem que a influência de relações comerciais realizadas por dirigentes afeta diretamente a internacionalização empresarial.

Palavras-chave: Empreendedorismo internacional. Internacionalização. Comercialização arrojada.

Abstract

In this research the overall objective was to analyze the international entrepreneurship in fruit exporters located in Northeastern Semiarid. The multiple case longitudinal study was developed based on the qualitative perspective. Companies from four states of the Northeastern Semiarid were analyzed, namely: Agrícola Famosa, Agro Melon (pseudonym) Special Fruit and Ara Agrícola. Thirty managers and consultants participated of semi-structured interviews, examined through content analysis. The results indicate that the bold marketing is a dimension of international entrepreneurship that emerged in the empirical stage of the research. The absence of contracts and the centralization of activities by the entrepreneur are the properties of bold marketing. These findings are relevant to the knowledge area of Management for revealing that the influence of trade relations made by leaders directly affect the business internationalization. Keywords: International entrepreneurship. Internationalization. Bold market.

\section{INTRODUÇÃO}

Entre as abordagens de internacionalização, o empreendedorismo internacional (EI) vem se destacando como uma perspectiva que colabora no desenvolvimento do campo de estudo. No Brasil, as investigações na área são incipientes, fato que desperta o interesse de pesquisadores nacionais.

Atualmente, observa-se que o empreendedorismo internacional é um fenômeno presente nas empresas novas, antigas, pequenas e grandes, porém, a maioria dos 
pesquisadores ainda continua a centralizar as pesquisas nas firmas jovens e pequenas (COOMBS; SADRIEH; ANNAVARJULA, 2009), o que, de alguma maneira, dificulta descobertas capazes de ajudar nos avanços da área. Nessa linha, com este trabalho se buscou contribuir, ao selecionar empresas maduras e de maior porte, na tentativa de identificar sutilezas do fenômeno.

Além disso, a maior parte da literatura de internacionalização é originada de nações desenvolvidas (JOHANSON; VAHLNE, 2009), existindo a necessidade de se ter propostas teóricas condizentes com o contexto de países emergentes (GAO et al., 2010). De modo geral, a elaboração de teorias que consideram as especificidades do contexto nacional é preliminar, sendo muitas das pesquisas tentativas frustradas de adequar a teoria produzida no exterior ao campo empírico brasileiro (BERTERO; KEINERT, 1994).

Por entender que se trata de um campo do conhecimento relativamente novo e, como salientado, necessita de consolidação (KEUPP; GASSMANN, 2009), nesta pesquisa teve-se o objetivo geral de analisar o empreendedorismo internacional nas exportadoras de frutas localizadas no Semiárido Nordestino. A seleção de empresas do setor da fruticultura ocorreu por atuarem num segmento econômico desafiador, no qual necessitam de ações empreendedoras constantes para se manterem competitivas diante do mercado internacional. Para tanto, a base teórica de EI apoiou o desenvolvimento do estudo, todavia, a intenção principal é revelar alguma(s) dimensão (ões) do EI específica(s) de exportadoras frutícolas.

\section{EMPREENDEDORISMO INTERNACIONAL}

A internacionalização pode ocorrer por diferentes causas. Na visão dos economistas, as motivações são decorrentes da fase do ciclo de vida do produto (VERNON, 1966), das imperfeições no mercado (HYMER, 1983) e do aumento da concorrência no país de origem (VERNON, 1966); enquanto no entendimento dos autores organizacionais a identificação de oportunidades (JOHANSON; VAHLNE, 1977), a estagnação do mercado interno (ROOT, 1994), a transação de recursos (PORTER, 1999), a tecnologia (DHANARAJ; BEAMISH, 2003), a cooperação entre rivais (PORTER, 1999), o tamanho da empresa (DHANARAJ; BEAMISH, 2003), o objetivo de prospectar vendas imediatas (ROOT, 1994), os incentivos governamentais do país hospedeiro (PORTER, 1999; ROOT, 1994 e as redes de relacionamentos (JOHANSON; VAHLNE, 2009; PORTER, 1999) são alguns dos motivos que levam uma empresa a se internacionalizar. 
Ao reconhecer os desafios que perpassam a internacionalização e o papel do dirigente nesse processo, o empreendedorismo internacional (EI) surge como uma orientação teórica que enfatiza questões que não foram amplamente discutidas nos modelos clássicos de internacionalização e empreendedorismo. Morrow (1988) foi o primeiro a escrever sobre o tema. Todavia, McDougall (1989) é considerada pioneira por realizar a primeira pesquisa teórico-empírica (ACS; DANA; JONES, 2003). Entrepreneurship Theory and Practice, Journal of Business Venturing, Journal of International Business Studies, Journal of Small Business Management e Small Business Economic divulgam com maior frequência artigos sobre empreendedorismo internacional. Observa-se, também, que no desenvolvimento, os autores tiverem focos distintos, e apenas Kiss, Danis e Cavusgil (2012) consideraram a revista especializada Journal of International Entrepreneurship. Por outro lado, salienta-se que Jones, Coviello e Tanz (2011) não indicaram a quantidade de artigos revisados por periódico, portanto, não são contemplados nessa explicação.

Ao se analisar o enfoque teórico dessas referências, são apontadas algumas considerações. A premissa principal desse campo é que a internacionalização é uma condição necessária para a sobrevivência do empreendimento (COOMBS; SADRIEH; ANNAVARJULA, 2009), e a comercialização com o exterior está no centro da discussão e traz vantagens empresariais, como a ampliação da possibilidade de lucro.

Quanto à classificação, de acordo com Jones, Coviello e Tang (2011), este estudo pode ser considerado do tipo A por se debruçar na investigação das ações empreendedoras, internacionalização, redes e estratégia (questões organizacionais). Para os autores, as pesquisas do tipo A são formadas por estudos de internacionalização empreendedora e estão voltadas para empreendedorismo, capital social, questões organizacionais, tipos de empreendimentos, internacionalização e redes. Já as do tipo B enfocam a comparação internacional de empreendedorismo, especificamente, comparam o empreendedorismo por países e/ou culturas, enquanto o tipo C aborda a comparação do empreendedorismo internacional entre nações ou culturas.

Destaca-se, também, que as pesquisas de EI realizadas nos países emergentes são examinadas por Kiss, Danis e Cavusgil (2012). Os autores analisaram 88 artigos publicados em 14 periódicos internacionais; perceberam, com isso, uma concentração significativa de pesquisas sobre a China e a Rússia e observaram que as empresas de países como Costa Rica, Jamaica e Chile se internacionalizam sistematicamente por um processo planejado.

O EI possui algumas características que o distingue do empreendedorismo tradicional. O empreendedorismo está relacionado à criação de um novo negócio por 
parte do empreendedor (FILION, 1999; OLIVEIRA, 2011); este é um entendimento também compartilhado pelo Global Entrepreneurship Monitor (KELLEY; BOSMA; AMORÓS, 2010). Mas no empreendedorismo internacional a questão não está apenas na criação de negócios, o ponto central consiste na forma em que ocorre o processo de internacionalização. O empreendedorismo internacional está presente nas firmas que se internacionalizam por meio de ações empreendedoras que podem ou não ser implementadas pelo proprietário (DIMITRATOS; PLAKOYIANNAKI, 2003).

O empreendedor é fundamental; com isso, Oliveira (2011, p. 2) ressalta a importância de entender que: “[...] o empreendedorismo se refere à ação de empreender, enquanto que o empreendedor é o indivíduo que executa tal ação.” Nesse aspecto, o empreendedorismo internacional é semelhante ao empreendedorismo tradicional, pois a sua existência depende de ações empreendedoras.

As atitudes do empreendedor na empresa para entregar produtos e serviços ao mercado internacional por meio da exportação com a fabricação doméstica ou de operação em países estrangeiros fazem do empreendedorismo internacional uma área do conhecimento distinta (MCDOUGALL, 1989).

Para aprofundar a discussão, realiza-se um exercício de reflexão com base nos conceitos de EI apresentados por autores que são referência na área (Quadro 1). Alguns construtos se destacam, a saber: atitude face ao risco, inovação, internacionalização, oportunidades internacionais, processo, recursos competitivos e vantagem competitiva.

Quadro 1 - Conceitos de Empreendedorismo Internacional

\begin{tabular}{|l|l|l|l|}
\hline Construtos-chave & Autores & Conceitos de EI & $\begin{array}{l}\text { Destaques do conceito } \\
\text { de EI }\end{array}$ \\
\hline \multirow{3}{*}{$\begin{array}{l}\text { Atitude face ao } \\
\text { risco }\end{array}$} & $\begin{array}{l}\text { “Um processo de criação de valor exer- } \\
\text { cido pela gestão corajosa na qual o enga- } \\
\text { jamento individual inovador, pró-ativo, }\end{array}$ & $\begin{array}{l}\text { - gestão corajosa } \\
\text { o comportamento favorável a enfrentar }\end{array}$ & - inovação \\
risco calculado projetado para processar & - proatividade \\
as oportunidades de negócios no exte- & - propensão ao risco \\
rior apresentadas pelas imperfeições e & calculado \\
sucesso do mercado multinacional e por & - oportunidades no \\
recompensas financeiras e não-financei- & exterior \\
\hline
\end{tabular}




\begin{tabular}{|c|c|c|c|}
\hline Inovação & $\begin{array}{l}\text { Mtigwe (2006) e } \\
\text { Zahra e George } \\
(2002)\end{array}$ & $\begin{array}{l}\text { “O processo de descoberta criativo e } \\
\text { exploração de oportunidades que se en- } \\
\text { contram fora dos mercados domésticos } \\
\text { de uma empresa na busca de vantagem } \\
\text { competitiva.” (ZAHRA; GEORGE, } \\
\text { 2002, p. 261). }\end{array}$ & $\begin{array}{l}\text { - processo } \\
\text { - descoberta de modo } \\
\text { criativo } \\
\text { - inovação no empreen- } \\
\text { dedorismo } \\
\text { - oportunidade fora do } \\
\text { mercado doméstico } \\
\text { - vantagem competitiva }\end{array}$ \\
\hline Internacionalização & $\begin{array}{l}\text { Coombs et al., } \\
\text { (2009) e Mc- } \\
\text { Dougall (1989) }\end{array}$ & $\begin{array}{l}\text { “[...] desenvolvimento de novas empre- } \\
\text { sas internacionais ou start-ups que desde } \\
\text { o início se engajam em negócios inter- } \\
\text { nacionais, assim tem suas operações de } \\
\text { domínio como internacionais desde os } \\
\text { estágios iniciais de operação da firma.” } \\
\text { (MCDOUGALL, 1989, p. 387). }\end{array}$ & $\begin{array}{l}\text { - restrito às novas } \\
\text { empresas e start-ups } \\
\text {-internacionalização } \\
\text { ocorre no início das } \\
\text { operações } \\
\text { - negócios internacio- } \\
\text { nais }\end{array}$ \\
\hline $\begin{array}{l}\text { Oportunidades } \\
\text { internacionais }\end{array}$ & $\begin{array}{l}\text { Dimitratos e } \\
\text { Plakoyiannaki } \\
\text { (2003), Mtigwe } \\
\text { (2006), Oviatt } \\
\text { e McDougall } \\
\text { (2005) e Zahra e } \\
\text { George (2002) }\end{array}$ & $\begin{array}{l}\text { Empreendedorismo internacional é um } \\
\text { processo de toda a organização que está } \\
\text { incorporado na cultura organizacional } \\
\text { da empresa e que procura, por meio da } \\
\text { exploração de oportunidades no mercado } \\
\text { internacional, gerar valor.” (DIMITRA- } \\
\text { TOS; PLAKOYIANNAKI, 2003, p. } \\
\text { 189). }\end{array}$ & $\begin{array}{l}\text { - processo } \\
\text { - como cultura organi- } \\
\text { zacional, seguido por } \\
\text { toda a empresa } \\
\text { - oportunidades no } \\
\text { mercado internacional } \\
\text { - geração de valor }\end{array}$ \\
\hline Processo & $\begin{array}{l}\text { Coombs et al., } \\
\text { (2009), Mtigwe } \\
(2006) \text { e } \\
\text { Zahra e George } \\
(2002)\end{array}$ & $\begin{array}{l}\text { [...] processo pelo qual os mercados } \\
\text { internacionais são usados na descoberta, } \\
\text { criação e/ou exploração de produtos } \\
\text { e serviços futuros.” (COOMBS; SA- } \\
\text { DRIEH; ANNAVARJULA, 2009, p. 26). }\end{array}$ & $\begin{array}{l}\text { - processo } \\
\text { - mercados interna- } \\
\text { cionais } \\
\text { - criação de produtos e } \\
\text { serviços }\end{array}$ \\
\hline $\begin{array}{l}\text { Recursos compe- } \\
\text { titivos }\end{array}$ & $\begin{array}{l}\text { Oviatt e McDou- } \\
\text { gall (1994) }\end{array}$ & $\begin{array}{l}\text { “Uma nova empresa internacional é } \\
\text { como uma organização de negócios, que, } \\
\text { desde o início, visa obter uma signifi- } \\
\text { cativa vantagem competitiva a partir da } \\
\text { utilização dos recursos e da venda de } \\
\text { resultados em vários países.” (OVIATT; } \\
\text { MCDOUGALL, 1994, p. 49). }\end{array}$ & $\begin{array}{l}\text { - restrito às novas } \\
\text { empresas } \\
\text { - internacionalização } \\
\text { ocorre no início das } \\
\text { operações } \\
\text { - vantagem competitiva } \\
\text { - destaca os recursos }\end{array}$ \\
\hline $\begin{array}{l}\text { Vantagem compe- } \\
\text { titiva }\end{array}$ & $\begin{array}{l}\text { Oviatt e McDou- } \\
\text { gall (1994) e } \\
\text { Zahra e George } \\
\text { (2002) }\end{array}$ & $\begin{array}{l}\text { “Empreendedorismo internacional é a } \\
\text { descoberta, a adoção, a avaliação e a } \\
\text { exploração de oportunidades, além das } \\
\text { fronteiras nacionais, para criar produtos } \\
\text { e serviços futuros.” (OVIATT; MCDOU- } \\
\text { GALL, 2005, p. 540). }\end{array}$ & $\begin{array}{l}\text { - oportunidades além } \\
\text { das fronteiras nacionais } \\
\text { - criação de produtos e } \\
\text { serviços (inovação) }\end{array}$ \\
\hline
\end{tabular}

Fonte: os autores.

No empreendedorismo internacional, o risco está no investimento realizado para atender ao mercado internacional, na negociação com os compradores que, 
muitas vezes, não tem garantias de pagamento (MCDOUGALL, 1989) e no modo de entrada no exterior (WELCH; WELCH, 2004). Embora tenha sido contemplada apenas na conceituação de Mtigwe (2006), a sua discussão é considerada por diferentes autores que serão apresentados ao longo do desenvolvimento desta seção. A atitude face ao risco, além de ser um fator preponderante na literatura clássica de empreendedorismo, vem ganhando espaço nos estudos de internacionalização. Tajeddini e Mueller (2009) argumentam que o comportamento de enfrentar os riscos faz parte das características do empreendedor, sendo uma das dimensões mais relevantes.

A inovação é também primordial, trata-se de um dos fatores que caracterizam o EI como área do conhecimento. Permite a identificação de oportunidades internacionais, delimita a configuração da cadeia de suprimentos, seleciona áreas a serem internacionalizadas, define caminhos únicos para passar valor ao consumidor e contribui na identificação de oportunidades (MTIGWE, 2006; ZAHRA; GEORGE, 2002). Essa proposta mais ampla se diferencia do que Oviatt e McDougall (2005) defendem, por limitar a inovação aos produtos e serviços comercializados internacionalmente.

A internacionalização é enfatizada em algumas das conceituações, o que está em completa conformidade com a proposta teórica do empreendedorismo internacional. As atividades empresariais se voltam ao exterior (COOMBS; SADRIEH; ANNAVARJULA, 2009) e podem iniciar o negócio motivadas por essa razão (MCDOUGALL, 1989).

O processo de exploração de oportunidades internacionais é um dos elementos-chave do empreendedorismo internacional. Dimitratos e Plakoyiannaki (2003) reconhecem o EI como um processo que ocorre em determinado contexto, aproximando-se do entendimento de Mtigwe (2006). Em relação às oportunidades no mercado internacional, Zahra e George (2002) defendem que a sua exploração pode ser influenciada pela criatividade empreendedora de vários membros do time gerencial. Enquanto para Dimitratos e Plakoyiannaki (2003) a identificação de oportunidades é insuficiente, a habilidade de explorá-las é essencial, argumento semelhante ao defendido por Oviatt e McDougall (2005).

A questão processual do empreendedorismo internacional é percebida por autores contemporâneos. Há pesquisadores que entendem o EI como um processo em si (COOMBS; SADRIEH; ANNAVARJULA, 2009), podendo também ser motivado pela busca para conquistar a criação de valor (MTIGWE, 2006) e descobrir oportunidades (ZAHRA; GEORGE, 2002). É um fenômeno que tende a ser melhor observado em um período mais longo de tempo, em razão do seu caráter processual. 
Os recursos competitivos apoiam a internacionalização (OVIATT; MCDOUGALL, 1994) para se alcançar a vantagem competitiva. Os recursos não apenas precisam ser heterogêneos e imóveis, mas, também valiosos, raros, insubstituíveis e inimitáveis - elementos do modelo VRII (BARNEY, 1991) - ou ter organização para explorá-los, constituindo o modelo VRIO (BARNEY, 2002). Nesse sentido, o capital financeiro, o físico, o humano e o organizacional são categorias de recursos. Quanto às capacidades, são reconhecidas como atributos internos da empresa que permitem a coordenação e exploração dos recursos, enquanto as competências favorecem à implementação das estratégias (BARNEY, 2002).

Para conquistar a vantagem competitiva, as ações do empreendedor no processo de internacionalização não estão restritas apenas ao crescimento da firma (PENROSE, 2006), mas englobam a sua diferenciação perante os concorrentes por meio da vantagem competitiva (BARNEY, 1991, 2002; PORTER, 1999; SHARMA; ERRAMILLI, 2004). Assim, a obtenção de vantagem competitiva é uma das preocupações centrais do EI (OVIATT; MCDOUGALL, 1994; ZAHRA; GEORGE, 2002) para se ter a “criação de valor” (DIMITRATOS; PLAKOYIANNAKI, 2003, p. 189; MTIGWE, 2006, p. 17) e permanecer no mercado.

Na ordem cronológica das publicações que conceituam o EI, são observados os avanços e contribuições de cada uma delas. A primeira denominação foi apresentada por McDougall (1989), que conseguiu delimitá-lo nas empresas novas ou start-ups que se internacionalizavam desde o início das operações. Aspecto compartilhado também por Oviatt e McDougall (1994), mas que tiveram o cuidado de complementar o conceito ao indicar a utilização de recursos e a venda em vários países como mecanismos para obter vantagem competitiva. Após oito anos, Zahra e George (2002) descartaram a visão limitada de se ter o EI restrito a novas empresas; na definição deles, a essência do termo está no processo de descoberta e exploração de oportunidades fora do país em busca da vantagem competitiva. Dimitratos e Plakoyiannaki (2003) concordam plenamente com Zahra e George (2002) e contribuem ao incorporar a cultura organizacional ao EI, o que significa um processo que engloba toda a empresa. O texto de Oviatt e McDougall (2005) se assemelha ao de Zahra e George (2002) e tem o propósito de não mais insistir no pressuposto original de ser o EI unicamente para novas empresas. Mtigwe (2006) apresenta uma abordagem bem mais completa que as dos autores anteriormente citados ao explicitar o papel do indivíduo inovador, proativo e que assume riscos, além de corroborar a importância da criação de valores e o acesso às oportunidades. Por fim, Coombs, Sadrieh e Annavarjula (2009) se restringem aos produtos e serviços de acordo com as necessidades dos mercados internacionais. 
Diante da revisão dos conceitos de EI apresentados no Quadro 1, pode-se alcançar uma compreensão conceitual acerca do fenômeno. Portanto, com base nessa análise,

[...] entende-se que o empreendedorismo internacional é resultante do processo de exploração de oportunidades internacionais, da inovação, da atitude face ao risco e do desenvolvimento de recursos competitivos por parte do empreendedor para obter vantagem competitiva com a internacionalização. (LEITE; MORAES, 2014).

\section{PROCEDIMENTOS METODOLÓGICOS}

A abordagem qualitativa foi considerada na realização desta pesquisa, observando-se o contexto (GODOY, 1995). A estratégia de estudo de múltiplos casos foi utilizada (EISENHARDT, 1989; MERRIAM, 1998), com a análise em retrospectivamente e longitudinal (COVIELLO; JONES, 2004; KISS; DANIS; CAVUSGIL, 2012). Em razão de tal complexidade do fenômeno, optou-se pelo uso do software ATLAS.ti.

Quatro empresas localizadas no Semiárido Nordestino - Agrícola Famosa (CE), Agro Melão (RN), Special Fruit (BA) e ARA Agrícola (PE) - foram selecionadas e analisadas. Após o estudo de cada uma das empresas, considerou-se o exame entre os casos, denominando-se análise cruzada dos casos. As empresas selecionadas exportam frutas frescas, como melão, manga e uva sem semente. Os sujeitos sociais e os casos foram selecionados pelo critério de conveniência, em razão do acesso às informações (MERRIAM, 1998).

Em relação aos respondentes, privilegiaram-se aqueles sujeitos sociais que dispunham de informações sobre a dinâmica competitiva da região do Semiárido, a respeito do segmento no qual atuam e sobre as decisões de investimentos e de implementação de estratégias internacionais. A quantidade de entrevistados foi definida quando as categorias atingiram o ponto de saturação adequado para responder aos objetivos da pesquisa (PAIVA JÚNIOR; LEÃO; MELLO, 2011), totalizando 30 sujeitos sociais e 31 entrevistas. As entrevistas foram gravadas e transcritas, perfazendo 1.242 minutos no total e uma média de 40 minutos por entrevistado, acontecendo em dois momentos distintos.

Além de entrevistas semiestruturadas, os dados foram coletados por análise de documentos e pesquisa bibliográfica (PATTON, 2001; TAYLOR; BOGDAN, 
1984). Anterior à coleta de dados, foi realizado um estudo piloto na Brazil Melon, localizada em Mossoró, RN. Indica-se que as anotações sobre o estudo piloto e a coleta de dados primários (entrevistas) foram registradas no diário de campo digital, em documento do Word.

Adotou-se a análise de conteúdo (BARDIN, 2011) para identificar as conexões, códigos e categorias existentes nas transcrições das entrevistas, considerando o contexto. Uma fase da análise ocorreu simultaneamente à coleta dos dados, por ser fundamental para os estudos qualitativos (TAYLOR; BOGDAN, 1984). Durante a análise de dados, houve a preocupação em se obter a validação e confiabilidade para que o resultado alcançado fosse o mais próximo possível da realidade e o método, passível de replicação, destacando-se a objetividade do estudo. Para alcançá-las, adotaram-se alguns critérios de validação e confiabilidade para pesquisa qualitativa indicados por Paiva Júnior, Leão e Mello (2011).

\section{ANÁLISE DOS RESULTADOS}

A partir da revisão teórica de EI e da utilização criteriosa do método científico, os dados foram analisados, e, como descoberta, observa-se que a comercialização arrojada desponta como uma nova dimensão do EI específica das exportadoras de frutas analisadas. Trata-se de uma dimensão que complementa as demais já identificadas em estudos anteriores. Nesta seção são apresentados os dados de cada uma das empresas para, em seguida, revelar-se a análise cruzada.

\subsection{ANÁLISE INDIVIDUAL DOS CASOS}

O ano de abertura, a localização, a quantidade de funcionários empregados no período de safra, a faixa de valor exportado em 2011 e a sigla das empresas são apresentados no Quadro 2. A Special Fruit é a firma com mais tempo de mercado, ao passo que a Ara Agrícola possui o menor tempo de atividade. A Agrícola Famosa emprega 5.000 pessoas, e a Agro Melão, 500, ambas têm o melão como principal produto exportado.

Ressalta-se que os representantes da Agrícola Famosa, Special Fruit e Ara Agrícola autorizaram a divulgação do nome da empresa na pesquisa mediante assinatura do termo de consentimento. A única exceção é a exportadora de Mossoró, RN, portanto, para garantir a confidencialidade exigida pelo gestor, a empresa está aqui nomeada Agro Melão. 
Quadro 2 - Apresentação sintética dos casos selecionados

\begin{tabular}{|c|c|c|c|c|}
\hline \multirow{2}{*}{ Características } & \multicolumn{4}{|l|}{ Empresas } \\
\hline & Agrícola Famosa & Agro Melão & Special Fruit & Ara Agrícola \\
\hline Abertura & 1995 & 1997 & 1982 & 2004 \\
\hline Localização & Icapuí, CE & Mossoró, RN & Juazeiro, BA & Petrolina, PE \\
\hline $\begin{array}{l}\text { Número de funcionários } \\
\text { (safra) }\end{array}$ & 5.000 & 500 & 1.700 & 1.000 \\
\hline Faixa de valor exportado em & Entre US\$ 50 e & Entre US\$ $1 \mathrm{e}$ & Entre US\$ $10 \mathrm{e}$ & Entre US\$ $10 \mathrm{e}$ \\
\hline 2011 & US\$ 100 milhões & US\$ 10 milhões & US\$ 50 milhões & US\$ 50 milhões \\
\hline Principais produtos exportados & Melão & Melão & Uva e manga & $\begin{array}{l}\text { Uva sem se- } \\
\text { mentes }\end{array}$ \\
\hline Sigla adotada no estudo & $\mathrm{AF}$ & AM & SF & ARA \\
\hline
\end{tabular}

Fonte: os autores.

A dimensão comercialização arrojada emerge da análise dos dados como um dos vértices da internacionalização da empresa (Esquema 1). A ausência de contratos reflete no desprendimento maior na seleção de compradores, pedido de adiantamento e incentivo à visita de importadores. Além dessas características, a participação em feiras internacionais, centralização e fonte de informação são elementos essenciais da comercialização arrojada.

Ressalta-se que na Agrícola Famosa essa dimensão se delineia com a presença de maior quantidade de propriedades quando comparada às três outras firmas analisadas. Nessa categoria, há influência e orientação comercial advindas do conhecimento e relacionamentos da fase de existência da trading exportadora, sendo esses elementos também reconhecidos como relevantes no início da internacionalização, por Oviatt e McDougall (1994). 
Esquema 1 - Propriedades da comercialização arrojada (Agrícola Famosa)

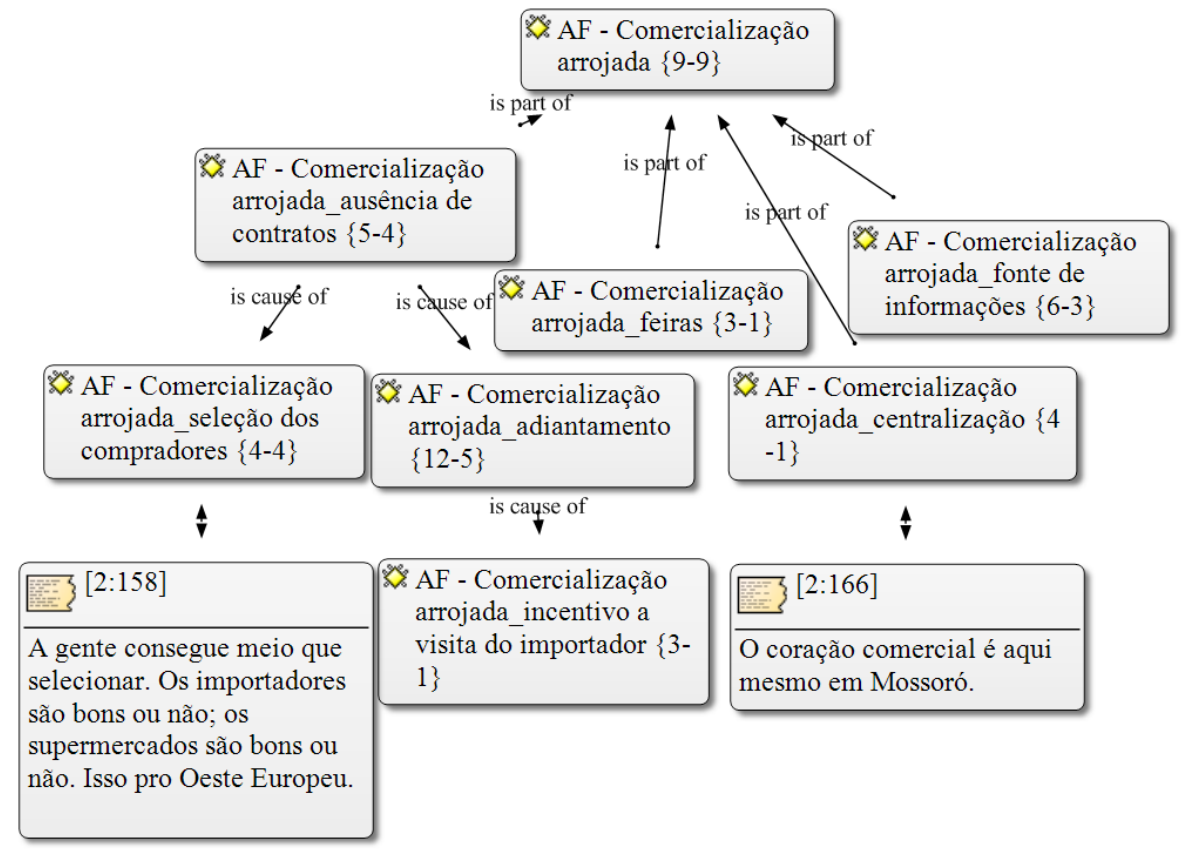

Fonte: os autores.

*Nota: os autores utilizaram o software ATLAS.ti para confeccionar o Esquema 1.

Na Agro Melão, a comercialização arrojada se estabelece na ausência de contratos e centralização das negociações para a venda dos produtos. No intuito de minimizar os riscos gerados pela falta de contratos formais, o empreendedor solicita adiantamento quando é viável e seleciona os compradores (Esquema 2).

A inexistência de transação em consignado nas empresas investigadas que exportam melão (Agrícola Famosa e Agro Melão) fortalece e traz competitividade organizacional, por extinguir um dos vértices de vulnerabilidade da exportação frutícola. Trata-se de uma ação empreendedora relevante e traz benefícios para a internacionalização; na visão de Welch e Welch (2004), a interpretação da dinâmica comercial é por si fonte de aprendizagem para o dirigente, observando-se, portanto, alinhamento entre os achados e a literatura. 
Esquema 2 - Propriedades da comercialização arrojada (Agro Melão)



Fonte: os autores.

*Nota: os autores utilizaram o software ATLAS.ti para confeccionar o Esquema 2.

Quanto à comercialização arrojada, na Special Fruit, em sua essência, é arriscada e se consolida mediante adiantamento, consignado, contratos, seleção dos compradores e determinação de preço firme (Esquema 3). Nessa empresa, existem contratos com alguns clientes - o mesmo resultado foi encontrado por Welch e Welch (2004) quando analisaram uma exportadora de açúcar -, porém, a transação não se limita muito a eles, a maioria das vendas é realizada sem a formalização contratual.

No Vale do São Francisco se pratica o consignado, que é arriscado e maléfico para as empresas por entregar a fruta sem preço predeterminado, assim, quando o produto não é vendido, para não haver custo de retorno (transporte) da fruta, vendem-na por qualquer preço, a fim de não a incinerar. A empresa vem trabalhando para mudar essa prática adotando o pedido de adiantamento e preço firme, isso quer dizer, o valor é fechado antes do envio da mercadoria ao porto. 
Esquema 3 - Propriedades da comercialização arrojada (Special Fruit)

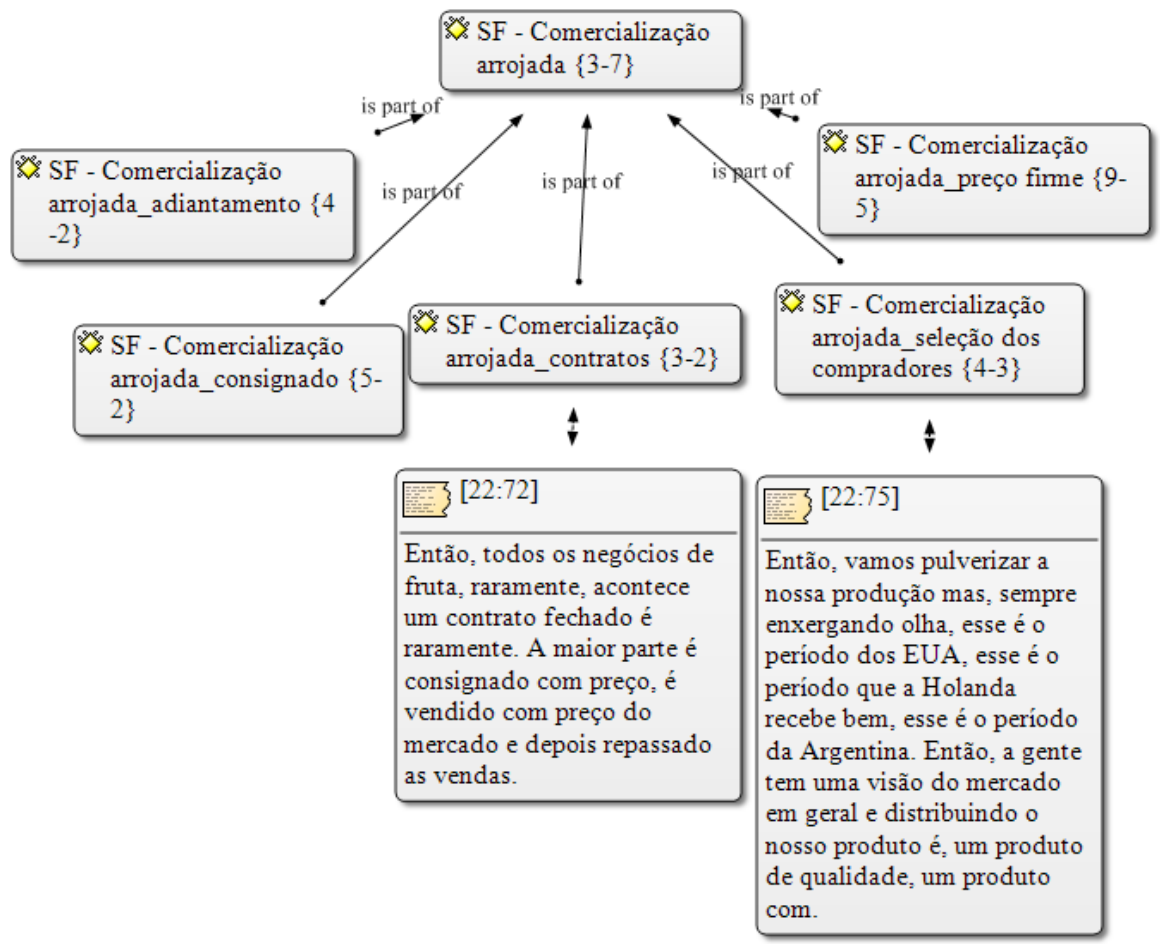

Fonte: os autores.

*Nota: os autores utilizaram o software ATLAS.ti para confeccionar o Esquema 3.

Por fim, na Ara Agrícola, a comercialização arrojada se assemelha ao da Special Fruit referente à implementação recente de adiantamento, preço firme e seleção dos compradores, e mantém em menor escala as práticas arriscadas do consignado e contratos (Esquema 4).

Percebe-se, com isso, certo movimento no direcionamento de bases mais concretas para minimizar os riscos do comércio frutícola, uma adaptação diante dos riscos de mercado. O enfrentamento de riscos desponta como uma característica do empreendedor que internacionaliza a empresa (SCHWEIZER; VAHLNE; JOHANSON, 2010). 
Esquema 4 - Propriedades da comercialização arrojada (Ara Agrícola)

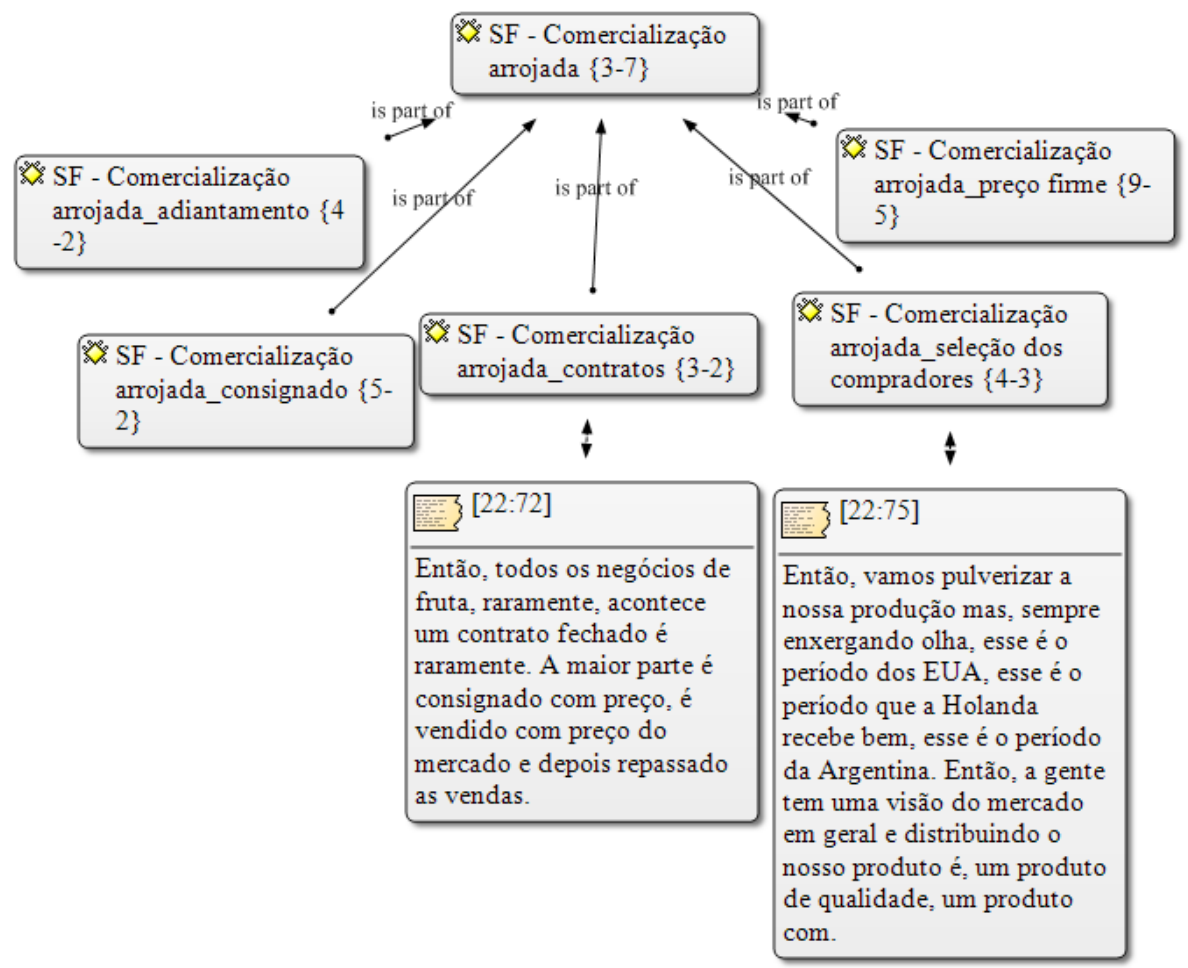

Fonte: os autores.

*Nota: os autores utilizaram o software ATLAS.ti para confeccionar o Esquema 4.

Portanto, o termo comercialização arrojada é igualmente adequado não apenas para as empresas do RN e CE que se posicionaram diante dos importadores com regras protetoras para o produtor, mas, também, para a Special Fruit e a Ara Agrícola, que se destacam no Vale do São Francisco por implementá-las.

\subsection{COMERCIALIZAÇÃO ARROJADA (ANÁLISE CRUZADA)}

A comercialização arrojada pode ser observada no EI quando os produtores frutícolas adotam a prática do adiantamento, selecionam os compradores (em razão da ausência de contratos) e centralizam a negociação comercial (Quadro 3), sendo essa uma das categorias, não prevista no modelo teórico, que emergiu da análise dos resultados.

Baseando-se nos dados empíricos, o adiantamento e a seleção dos compradores são ações realizadas para minimizar os riscos com o objetivo de garantir o recebimento da venda efetivada ao exterior. Nesse contexto, compreende-se por 
adiantamento o pagamento antecipado dos produtos negociados com compradores do exterior recebidos antes do embarque. Já a seleção dos compradores, neste escopo, envolve a escolha de clientes com maior probabilidade de efetivar o pagamento.

A pesquisa realizada por Welch e Welch (2004) no setor do agronegócio, embora não enfatize diretamente a comercialização, chama atenção para a importância do governo do país de origem na colaboração política de apoio às exportações de açúcar. Nesse aspecto, os resultados desta investigação se alinham parcialmente, visto que nas décadas de 1970 e 1980 existiu apoio governamental para a agricultura no Vale do São Francisco e região de Mossoró, RN, com incentivos fiscais e financiamentos. De 1990 aos tempos atuais, pode-se considerar que os agentes políticos brasileiros pouco fizeram, principalmente, quando o assunto é o cultivo de frutas para exportação.

Quadro 3 - Definição das propriedades e características da comercialização arrojada

\begin{tabular}{|c|c|c|c|c|c|}
\hline \begin{tabular}{|l|} 
Propriedades \\
(Comercialização Arrojada)
\end{tabular} & Características & $\begin{array}{l}\text { Agrícola } \\
\text { Famosa }\end{array}$ & $\begin{array}{l}\text { Agro } \\
\text { Melão }\end{array}$ & \begin{tabular}{|l|} 
Special \\
Fruit
\end{tabular} & $\begin{array}{l}\text { Ara Agrí- } \\
\text { cola }\end{array}$ \\
\hline \multirow{3}{*}{ Ausência de contratos } & Adiantamento & & & & \\
\hline & Seleção dos compradores & & & & \\
\hline & $\begin{array}{l}\text { Incentivo à visita do impor- } \\
\text { tador }\end{array}$ & & & & \\
\hline Centralização & |----------------- & & & & \\
\hline Consignado & |------------------ & & & & \\
\hline Contratos & Preço firme & & & & \\
\hline Feiras & |------------------ & & & & \\
\hline Fonte de informações & |------------------ & & & & \\
\hline
\end{tabular}

Fonte: os autores.

*Nota: os autores utilizaram o software ATLAS.ti para confeccionar o Quadro 3.

Em relação à centralização, o termo está atrelado à concentração da estrutura física do comercial e das negociações mercadológicas no líder. Nas empresas examinadas, os próprios empreendedores estão à frente das negociações com os clientes internacionais e mantêm a estrutura física dentro da fazenda, independentemente da quantidade de clientes e volume exportado. Nas firmas em que a atuação empreendedora se destaca, tende-se a centralizar o poder de decisão (SOHN; LENZI; KIESEL, 2004).

As características da indústria, ressaltam Kiss, Danis e Cavusgil (2012), podem ter impeditivos ou facilitadores para a internacionalização, cabe ao empreendedor avaliá-las e definir estratégias condizentes ao contexto. Entende-se, então, a comercialização arrojada como uma categoria de resposta à dinâmica de exportação frutícula que possui particularidades próprias em razão da falta de proteção comercial para o exportador. Desse modo, indica-se que comercialização arrojada é uma dimensão do empreendedorismo internacional. 


\section{CONSIDERAÇÕES FINAIS}

Ao considerar o objetivo geral de analisar o empreendedorismo internacional nas exportadoras de frutas localizadas no Semiárido Nordestino, percebeu-se que a comercialização arrojada é uma nova dimensão que desponta no EI. Diante de tal análise, alcança-se a seguinte proposição: a comercialização arrojada é uma dimensão do empreendedorismo internacional.

A ausência de contratos e a centralização são as propriedades da comercialização arrojada. Isso significa que diante da ausência de contratos os empreendedores delimitam o adiantamento e selecionam os compradores para enfrentar os competidores internacionais que são experientes no setor. Os riscos das transações comerciais por falta de contratos são minimizados pelo fortalecimento das redes de relacionamentos com os compradores e agentes internacionais. O desenvolvimento dessas relações mitiga as perdas financeiras com a negociação comercial, no caso dos clientes, passam a ser parceiros, e os agentes fornecem informações essenciais sobre o mercado.

Quanto à centralização, trata-se da atuação do empreendedor nas negociações com os clientes estrangeiros. Mesmo com a existência do setor comercial com uma equipe treinada, os empreendedores estão presentes na consolidação dos acordos e exigem que os compradores os conheçam pessoalmente. Essa atitude segue o propósito crucial de se aproximar dos compradores em busca da diminuição do risco das transações comerciais.

Observa-se que diante da natureza do produto comercializado, frutas in natura, o risco de perda é elevado. Assim, a forma de comercialização tem papel fundamental, sendo um fator dependente das ações empreendedoras para permanecer no mercado internacional. Portanto, observa-se que a contribuição deste estudo está na identificação do processo de comercialização como uma atividade estratégica para exportadoras frutícolas. Diante disso, indica-se a realização de pesquisas em firmas do agronegócio que negociem outros produtos, para analisar se a comercialização arrojada pode ser considerada uma dimensão do empreendedorismo internacional.

\section{REFERÊNCIAS}

ACS, Z.; DANA, L-P.; JONES, M. V. Toward new horizons: the internationalisation of entrepreneurship. Journal of International Entrepreneurship, v. 1, i. 1, p. 5-12, 2003. 
AUTIO, E.; GEORGE, G.; ALEXY, O. International entrepreneurship and capability development: qualitative evidence and future research directions. Entrepreneurship Theory \& Practice, v. 35, i. 1, p. 11-37, 2011.

BARDIN, L. Análise de Conteúdo. São Paulo: Edições 70, 2011.

BARNEY, J. B. Firm resources and sustained competitive advantage. Journal of Management, v. 17, i. 1, p. 99-120, 1991.

BARNEY, J. B. Gaining and sustaining competitive advantage. 3. ed. New Jersey: Prentice-Hall, 2002.

BERTERO, C. O.; KEINERT, T. M. M. A evolução da análise organizacional no Brasil. Revista de Administração de Empresas, v. 34, n. 3, p. 81-90, 1994.

BOGDAN, R. C.; BIKLEN, S. K. Investigação qualitativa em educação. Porto: Porto Editora, 1994.

COOMBS, J. E.; SADRIEH, F.; ANNAVARJULA, M. Two decades of international entrepreneurship research: what have we learned - where do we go from here? International Journal of Entrepreneurship, v. 13, i. 1, p. 23-64, 2009.

COVIELLO, N. E.; JONES, M. V. Methodological issues in international entrepreneurship research. Journal of Business Venturing, v. 19, i. 1, p. 485-508, 2004.

DHANARAJ, C.; BEAMISH, P. W. A resource-based approach to the study of export performance. Journal of Small Business Management, v. 41, i. 3, p. 242-261, 2003.

DIMITRATOS, P.; PLAKOYIANNAKI, E. Theoretical foundations of international entrepreneurial culture. Journal of International entrepreneurship, v. 1, i. 2, p. 187-215, 2003.

DUNNING, J. H. The eclectic paradigm of international production: a restatement and some possible extensions. Journal of International Business Studies, v. 19, i. 1, p. 1-31, 1988.

EISENHARDT, K. M. Building theories from case studies research. Academy Management Review, v. 14, i. 4, p. 532-550, 1989. 
FILION, L. J. Empreendedorismo: empreendedores e proprietários-gerentes de pequenos negócios. Revista de Administração, São Paulo, v. 34, n. 2, p. 5-28, abr./ jun. 1999.

GAO, G. Y. et al. “Strategy tripod” perspective on export behaviors: Evidence from domestic and foreign firms based in an emerging economy. Journal of International Business Studies, Washington, v. 41, i. 3, p. 377-395, Apr. 2010.

GODOY, A. S. Introdução à pesquisa qualitativa e suas possibilidades. Revista de Administração de Empresas, São Paulo, v. 35, n. 2, p. 57-63, mar./abr. 1995.

GUBA, E. G.; LINCOLN, Y. S. Paradigmatic controversies, contradictions, and emerging confluences. In: DENZIN, N. K.; LINCOLN, Y. S. (Ed.). Handbook of Qualitative Research. 3rd ed. London: Sage, 2005.

HYMER, Stephen. Empresas multinacionais: a internacionalização do capital. 2. ed. Rio de Janeiro: Edições Graal, 1983.

JOHANSON, J.; VAHLNE, J-E. The internationalization process of the firm: a model of knowledge development and increasing foreign markets commitments. Journal of International Business Studies, v. 8, i. 1, p. 23-32, Spring 1977.

JOHANSON, J.; VAHLNE, J-E. The Uppsala internationalization process model revisited: from liability of foreignness to liability of outsidership. Journal of International Business Studies, v. 40, i. 9, p. 1411-1431, 2009.

JONES, M. V.; COVIELLO, N.; TANG, Y. K. International entrepreneurship research (1989-2009): a domain ontology and thematic analysis. Journal of Business Venturing, v. 26, i. 1, p. 632-659, 2011.

KELLEY, D. J.; BOSMA, N.; AMORÓS, J. E. Global Entrepreneurship Monitor: 2010 global report. 2010.

KEUPP, M. M.; GASSMANN, O. The past and the future of international entrepreneurship: a review and suggestions for developing the field. Journal of Management, v. 35, i. 3, p. 600-633, June 2009.

KISS, A. N.; DANIS, W. M.; CAVUSGIL, S. T. International entrepreneurship research in emerging economies: a critical review and research agenda. Journal of Business Venturing, v. 27, i. 2, p. 266-290, Mar. 2012. 
LEITE, Y. V. P.; MORAES, W. F. A. de. Propensão à Adaptação no Empreendedorismo Internacional: uma Análise Qualitativa de Exportadoras do Semiárido. In: ENCONTRO DA ENANPAD, 38., 2014, Rio de Janeiro. Anais... Rio de Janeiro, 2014. Disponível em: <http://www.anpad.org.br/admin/pdf/2014_EnANPAD_ESO219. pdf>. Acesso em: 08 jun. 2015.

MCDOUGALL, P. P. International versus domestic entrepreneurship: new venture strategic behavior and industry structure. Journal of Business Venturing, v. 4, i. 6, p. 387-400, 1989.

MERRIAM, S. B. Qualitative research and case study applications in education. San Francisco: Jossey-Bass, 1998.

MORROW, J. F. International entrepreneurship: A new growth opportunity. New Management, v. 5, i. 3, p. 59-60, 1988.

MTIGWE, B. Theoretical milestones in international business: the journey to international entrepreneurship theory. Journal of International Entrepreneurship, v. 4, i. 1, p. 5-25, 2006.

OLIVEIRA, M. de F. S. El concepto del empreendedorismo: ¿todavía un problema? In: ENCONTRO DA ANPAD, 35., Rio de Janeiro, 2011. Anais... Rio de Janeiro: EnAnpad, 2011.

OVIATT, B. M.; MCDOUGALL, P. P. Defining international entrepreneurship and modeling the speed of internationalization. Entrepreneurship Theory \& Practice, v. 29, i. 5, p. 537-553, 2005.

OVIATT, B. M.; MCDOUGALL, P. P. Toward a theory of international new ventures. Journal of International Business Studies, v. 25, i. 1, p. 45-64, 1994.

PAIVA JÚNIOR, F. G. de; LEÃO, A. L. M. de S.; MELLO, S. C. B. de. Validade e Confiabilidade na Pesquisa Qualitativa em Administração. Revista de Ciências da Administração, v. 13, n. 31, p. 190-209, set./dez. 2011.

PATTON, M. Q. Qualitative research and evaluation methods. Califórnia: Sage Publication, 2001.

PENROSE, E. A teoria do crescimento da firma. Campinas: Ed. Unicamp, 2006. 
PORTER, M. E. A vantagem competitiva das nações. In: PORTER, M. E. (Ed.). Competição: estratégias competitivas essenciais. 6. ed. Rio de Janeiro: Campus, 1999.

PORTER, M. E. Estratégia competitiva: técnicas para análise de indústrias e da concorrência. Rio de Janeiro: Campus, 1986.

ROOT, F. R. Design entry strategy for international markets. In: ROOT, F. R. (Ed.). Entry strategies for international markets. New York: Lexington Books, 1994.

SCHWEIZER, R.; VAHLNE, J. E.; JOHANSON, J. Internationalization as an entrepreneurial process. Journal of International Entrepreneurship, v. 8, i. 4, p. 343370, 2010.

SHARMA, V. M.; ERRAMILLI, M. K. Resource-based explanation of entry mode choice. Journal of Marketing Theory and Practice, v. 12, i. 1, p. 1-18, Winter 2004.

SOHN, A. P. L.; LENZI, F. C.; KIEZEL, M. D. A presença do espírito empreendedor no processo de formulação de estratégias de internacionalização da Datasul. In: ENCONTRO DA ANPAD, 28., Curitiba, 2004. Anais... Curitiba: EnAnpad, 2004.

TAJEDDINI, K.; MUELLER, S. L. Entrepreneurial characteristics in Switzerland and the UK: a comparative study of techno-entrepreneurs. Journal of International Entrepreneurship, v. 7, i. 1, p. 1-25, 2009.

TAYLOR, S. J.; BOGDAN, R. Introduction to qualitative research methods: the search for meanings. 2. ed. New York: John Wiley \& Sons, 1984.

VERNON, R. International investment and international trade in the product cycle. Quarterly Journal of Economics, v. 80, i. 2, p. 191-207, 1966.

WELCH, C.; WELCH, L. S. Broadening the concept of international entrepreneurship: internationalization, networks and politics. Journal of International Entrepreneurship, v. 2, i. 3, p. 217-237, Sept. 2004.

ZAHRA, S. A.; GEORGE, G. International entrepreneurship: the current status of field and future research agenda. In: HITT, M. A. et al. (Ed.). Strategic entrepreneurship, creating a new mindset. Oxford: Blackwell, 2002. 
Como citar este artigo:

ABNT

LEITE, Yákara Vasconcelos Pereira; MORAES, Walter Fernando Araújo; SALAZAR, Viviane Santos. Empreendedorismo internacional: uma análise de exportadoras de semiárido nordestino. RACE, Revista de Administração, Contabilidade e Economia, Joaçaba: Ed. Unoesc, v. 15, n. 2, p. 531-552, maio./ago. 2016. Disponível em: <http://editora.unoesc.edu.br/index.php/race>. Acesso em: dia/mês/ano.

\section{APA}

Leite, Y. V. P., Moraes, W. F. A., \& Salazar, V. S. (2016). Empreendedorismo internacional: uma análise de exportadoras de semiárido nordestino. RACE, Revista de Administração, Contabilidade e Economia, 15(2), 531-552. Recuperado de http:// editora.unoesc.edu.br/index.php/race 